\title{
Editorial
}

\section{Geochemistry of Aquatic Sediments}

\author{
Stanislav Frančišković-Bilinski, ${ }^{1}$ Marc Schwientek, ${ }^{2}$ and Amir Sandler ${ }^{3}$ \\ ${ }^{1}$ Division for Marine and Environmental Research, Institute "Ruđer Bošković", P.O. Box 180, 10002 Zagreb, Croatia \\ ${ }^{2}$ Center of Applied Geoscience, Eberhard Karls University of Tübingen, Hölderlinstr. 12, 72074 Tübingen, Germany \\ ${ }^{3}$ Geological Survey of Israel, 30 Malkhe Israel St, 95501 Jerusalem, Israel
}

Correspondence should be addressed to Stanislav Frančišković-Bilinski; francis@irb.hr

Received 9 November 2016; Accepted 9 November 2016; Published 10 January 2017

Copyright (C) 2017 Stanislav Frančišković-Bilinski et al. This is an open access article distributed under the Creative Commons Attribution License, which permits unrestricted use, distribution, and reproduction in any medium, provided the original work is properly cited.

The type and composition of freshwater and marine sediments are key factors in environmental research of (a) natural processes such as sediment transport and accumulation, biodiversity, and biogeochemical reactions within sediments and (b) evaluation of source and progress of contamination, as aquatic sediments act as a sink for nonorganic and organic toxic substances. Above certain levels, such substances could harm biological diversity and human health. Geochemical investigations of aquatic sediments in fluvial, lacustrine, estuarine, and marine environments are of fundamental interest for the assessment of natural ecosystems and the level of pollution that potentially harms them. Detailed determination of the chemical constituents of aquatic sediments assists in detecting sources of pollution as sewage, industry, agriculture, abandoned and active mines, landfills, harbor activities, and oil drilling [leakage]. In addition, natural anomalies may indicate mineral resources in a particular region.

New methods and approaches for sampling and analysis are continuously being introduced in aquatic sediment research. More attention is given to qualitative and quantitative monitoring of sediment and sediment fluxes, which is regularly established in most European countries and many others worldwide. Unfortunately, uniform legislation of sediment quality [and load] still does not exist on an international level and in most countries does not exist even on the national level. Therefore, more attention should be given to further expansion of sediment monitoring and of establishing criteria for assessing sediment quality and legislative for toxic inorganic and organic pollutants.
The aim of this special issue is to present up-to-date studies on aquatic sediments from different environments in different parts of the world. Six of the seven selected papers deal with different aspects, mostly various pollutants, present in terrestrial aquatic sediments, whereas one of them focusses on marine sediments. In one of the papers of this special issue, L. Kalender and G. Aytimur address rare earth elements (REE) geochemistry of the Euphrates River, Turkey. This paper presents REE concentrations for the first time, along with source rock composition of the Euphrates River sediments and waters and provides a significant contribution for a better understanding of REE behavior in river sediments. The paper of W. Jingfu et al. deals with sulfur (S) speciation in the surface sediments of lakes from different regions of China, using $\mathrm{S}$ K-Edge XANES spectroscopy, which has unique advantages in morphological analysis of $\mathrm{S}$ in sediments. M. Nasr and P. A. Arp investigate mercury and organic matter concentrations in lake and stream sediments across Canada. Their most significant finding is that lake and stream sediments enriched with organic matter are more sensitive to atmospheric $\mathrm{Hg}$ deposition than sediments with no to little organic matter content. In their research article J. He et al. demonstrate how composition and distribution characteristics of $n$-alkanes in marine sediments may be used to indicate the n-alkanes' origin, sedimentation conditions, and the impact of microbial degradation. M. Cangemi et al. present geochemical and isotopic characteristics of actual lacustrine sediments from the hydrothermal lake Specchio di Venere on Pantelleria Island, Italy. The novel data from their research about major, minor, and trace elements and isotopic 
composition (carbonate phases) of these sediments give new insights into the different factors contributing to the chemical sedimentation into the lake. P. S. Loh et al. investigate sedimentary organic matter and phosphate along the Kapuas River in West Kalimantan, Indonesia, which is the world's longest river on an island. They find that phytoplankton blooms and high organic matter $(\mathrm{OM})$ decomposition rates most likely occurred along the downstream Kapuas River where the sedimentary OM was fresher and more bioavailable and the P level was the highest. In another article of this special issue, D. M. Prieto et al. acquaint us with their research on arsenic transfer from As-rich sediments to river water in the presence of biofilms. They contribute to the overall knowledge of the role of biofilms in As biogeochemistry in riverine systems.

Considering the current special issue we think the selected articles offer an ideal opportunity to update our knowledge on different aspects of geochemistry of aquatic sediments.

Stanislav Frančišković-Bilinski Marc Schwientek Amir Sandler 

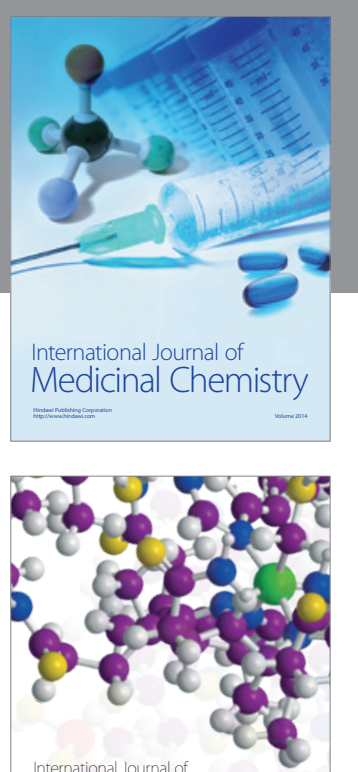

Carbohydrate Chemistry

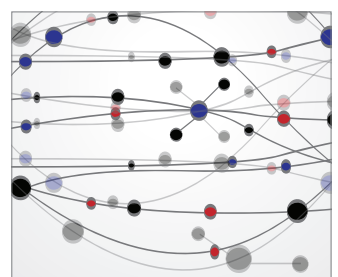

The Scientific World Journal
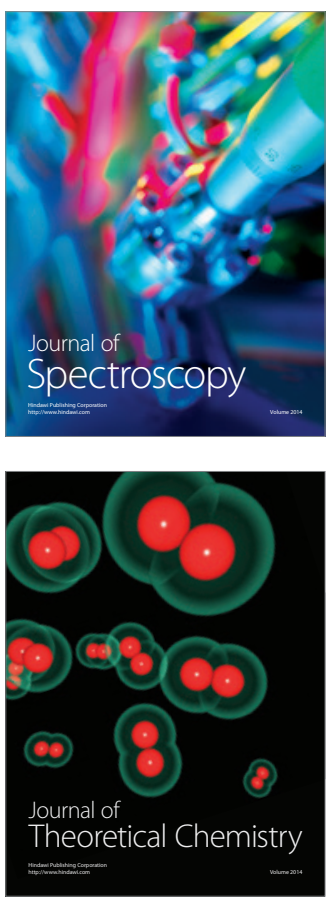
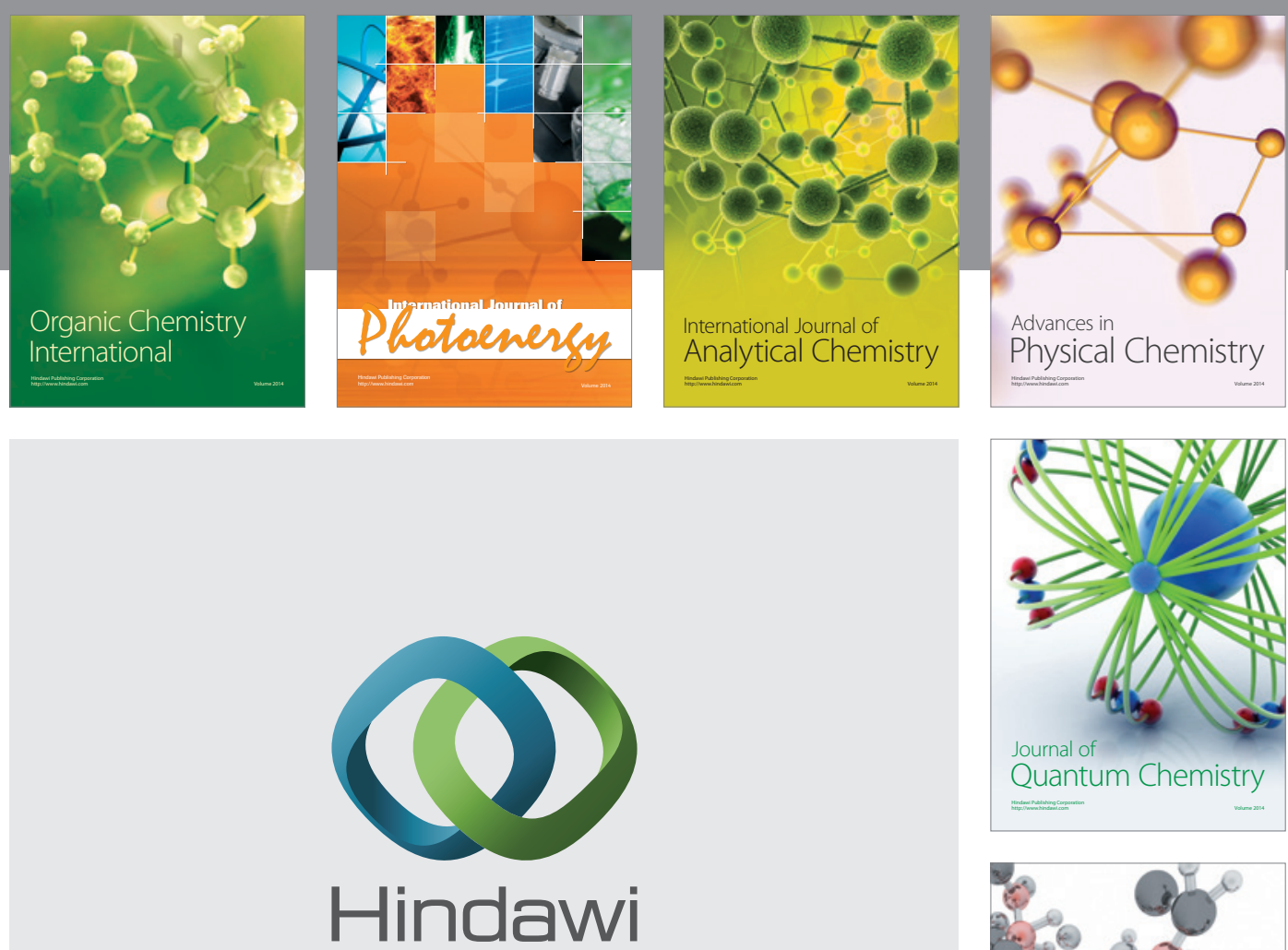

Submit your manuscripts at

https://www.hindawi.com

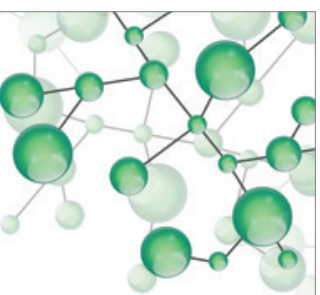

International Journal of

Inorganic Chemistry
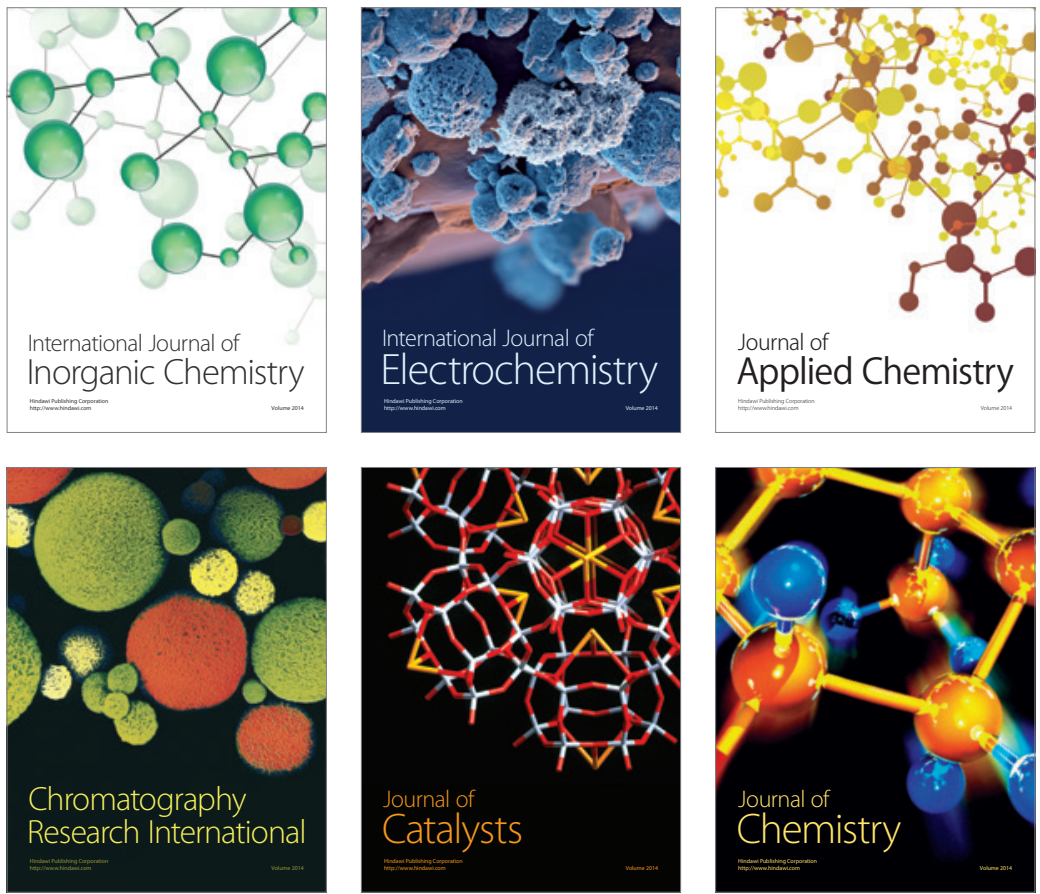

Journal of

Applied Chemistry
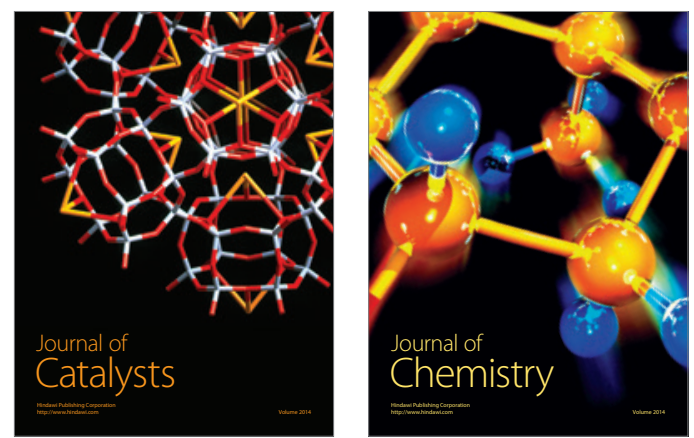
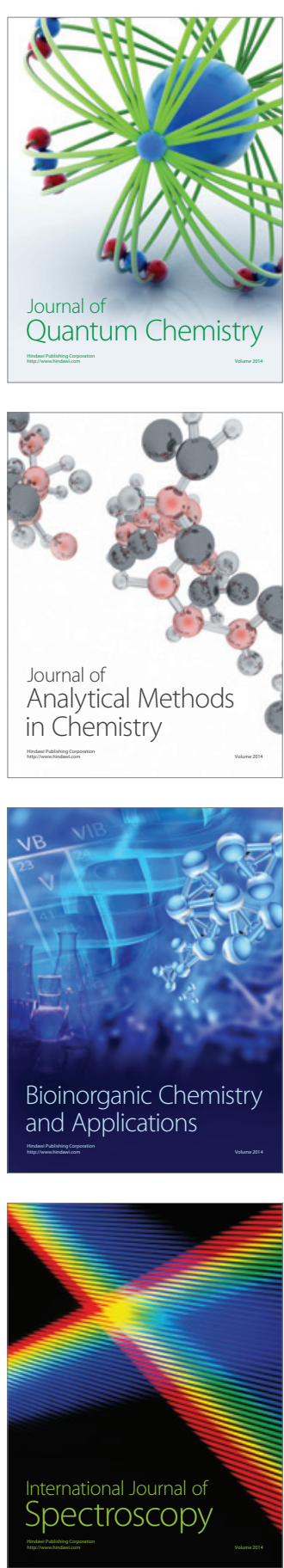